\title{
Reasonable Analysis of Enterprise Internal Control Economy Based on Enterprise Risk and Cost Benefit Principle
}

\author{
Liyuan Zhou \\ Easten Liaoning University, Dandong, Liaoning 118001 China. \\ Inczzly@163.com
}

\begin{abstract}
The possibility of sustainable development of an enterprise must be based on sound internal control. Based on the requirements of risk prevention and maximization of benefits, different management methods are established according to different levels and different levels of risk, and accurate identification and evaluation are carried out. On the basis of risk, weigh the pros and cons, seize the major risks to carry out special control, and ensure the effective implementation of internal control through information technology to achieve cost savings and maximize benefits.
\end{abstract}

Keywords: Enterprise risk; Cost-effectiveness; Value creation; internal control.

\section{Introduction}

Internal control is a topic that cannot be ignored in modern enterprise management. Sound and effective internal control has a very important impact on the short-term balance and long-term development of enterprises. How to scientifically design an effective internal control system, without wasting resources and achieving results, is a problem that enterprise management should attach great importance to. This paper takes the basic framework of internal control as the guide, analyzes the current situation of cost and expense management, objectively evaluates the soundness of its control system and the effectiveness of its implementation, and explores the problems existing in the process of cost control. From the perspective of internal control, it proposes an institutional system and optimization measures that are conducive to improving the cost control of enterprises and provides assistance for strengthening internal control management of cost and expenses, reducing operating costs, and improving profit margin and market competitiveness. At the same time, we also hope to provide a case reference for the internal control optimization of cost and expense for the same type of enterprises.

\section{Internal Control Interpretation}

According to the US COSO Committee, internal control is implemented by the company's board of directors, managers, and other employees to provide a reasonable assurance process for the efficiency of the company's operations, the reliability of financial reporting, and the compliance of relevant laws and regulations. Internal control includes five elements: control environment, risk assessment, control activities, information and communication, and monitoring. According to the above statement, internal control means that in order to achieve business management objectives, enterprises ensure that management activities are carried out efficiently, protect the safety and integrity of property materials, improve the quality of accounting information, and ensure relevant laws, regulations, rules and regulations, and business management. A series of methods, measures and procedures for mutual control and coordination of various business management activities within the enterprise.

\section{Necessity and Relationship between Internal Control Risk Management and Cost-Effectiveness}

\subsection{Necessity Analysis}

Enterprises are aiming at maximizing profits. In the process of achieving the goals, enterprises will continue to increase efficiency by reducing costs and improving efficiency. Comprehensive income 
is an indicator of a company's performance and has an advantage in that it is closer to economic efficiency. The comprehensive income integrates the fair value into the process of corporate income, taking into account the gains and losses. Internal control is also an effective tool and method for achieving profit maximization goals. A sound internal control system can guarantee the profitability and integrity of the assets; ensure the reliability of accounting information to avoid false and misleading statements; ensure that the company will not violate the laws and regulations within its business scope and prevent the company from being Manage and manage risks, reduce losses, and ensure comprehensive income.

\subsection{Relationship Analysis}

In order to make the risk prevention function in internal control play, it is necessary to pay the corresponding execution cost, and the input cost of execution cost is negatively correlated with the risk, that is, the more human and financial resources invested in risk prevention and control, the more control The better the effect will be, the more the risk will decrease, the less risk the company will have; however, the business risk of the company is positively related to the expected return of the company under certain conditions, that is, sometimes the internal control of the enterprise resolves the risk. It also destroys the value. The relationship between risk prevention and cost-effectiveness in the operation of internal control of enterprises is shown in the following figure.

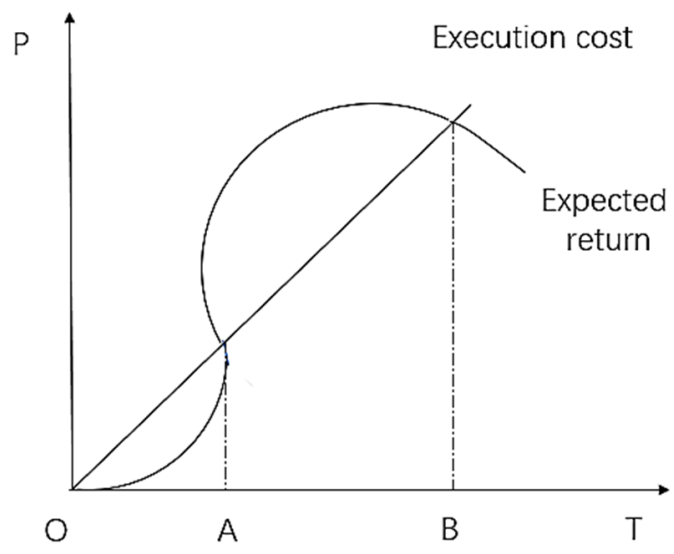

Fig 1. Relationship between internal control costs and corporate consolidation goals

First, in the OA phase, which is the initial stage of the internal control system construction, the input of internal control construction is greater than the expected return. Internal controls have direct compliance costs and other costs during the first company execution. The direct compliance costs include the establishment of the internal control system of the enterprise, the improvement of the original internal control system, the training of all internal control personnel, the duplication of work or waste due to the internal control plan of the enterprise or the lack of scientific design, and the increase of audit and consulting fees. The related costs caused by the cause[1]. In addition to direct compliance with costs, there are indirect costs for companies to implement internal controls, such as friction costs between employees, departments, and between companies and customers. At this stage, the internal control execution has not been fully in place, and it has not played a good role in preventing the risk, which is reflected in the missing state. In the $\mathrm{AB}$ phase, the company has established an effective internal control system and operates effectively. The internal control system effectively guards against risks, and the expected benefits are far greater than the implementation costs, which is reflected in the moderate state. In the BT stage, enterprises are paying too much attention to risks, taking the risk of enterprises as the starting point, and continuously strengthening the risk prevention by strengthening internal control of enterprises, which will make the internal control of enterprises into an excessive stage. For example, too many approval links are set up, and in order to prevent market risks from abandoning development opportunities, etc., they are excessive internal control. 


\subsection{Comprehensive Internal Control between Cost-Effectiveness and Enterprise Risk Control}

As an economic organization, the ultimate goal of the enterprise is to maximize profits and maximize economic benefits. Therefore, in the process of establishing an internal control system, an enterprise must consider the requirements of the overall goal: to save costs and reduce costs as much as possible while ensuring the effectiveness of internal control and achieving the set goals, that is, to solve the cost-effective problem first. It is generally believed that the relationship between internal control costs and benefits is that internal control costs increase as the benefits of internal control increase. However, the magnitude of the increase is different. The internal control cost is first reduced and then increased. The internal control benefit is increased first and then decreased, and the internal control gain is expressed as a function of cost as $R=f(C)$.

However, internal control is an important part of risk management. The analysis of internal control cannot be based solely on cost and benefit. It is also necessary to introduce the concept of risk control as an accidental factor, that is, to study the effective implementation of internal control for potential risks[2]. The prevention and avoidance of losses can be included in the measurement of benefits, and the internal control benefit function can be expressed as $R=f(C)+\sigma$.

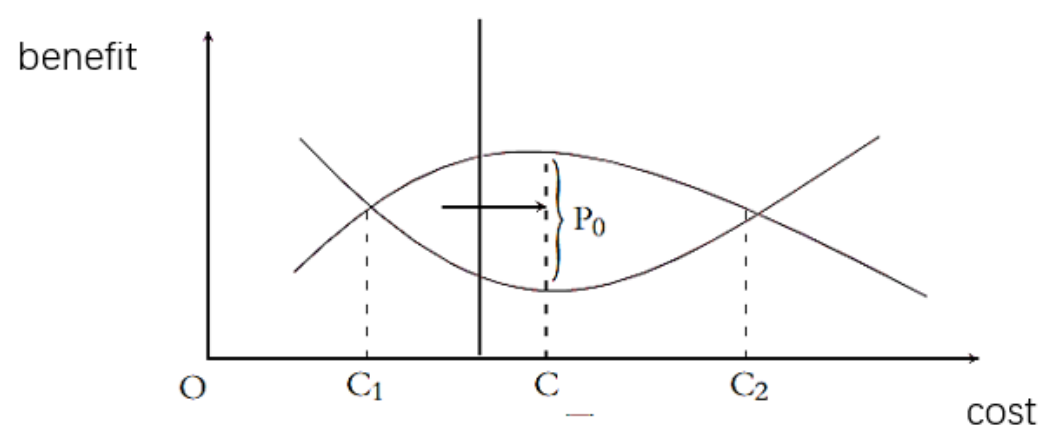

Fig 2. Comprehensive cost control and risk internal control

Considering the cost-benefit principle of internal control, it is necessary to find a feasible combination of cost and benefit of risk loss prevention $\left(C_{1}-C_{2}\right)$. Within this interval, the marginal cost of improving the internal control level of the enterprise is less than or equal to the marginal benefit. Exceeding this interval, there is no economic significance for the enterprise to raise the internal control level. Using economic theory, we can find the cost balance point that maximizes the profit $(P)$ of the internal control implementation of the enterprise $(C)$. That can be expressed by publicity: $R=f(C)+\sigma-C$. In Figure $2, P_{0}$ is the maximum value of $P$. The condition is that the first-order $P$ derivative function is 0 , and the marginal benefit is equal to the marginal cost $(\mathrm{MR}=\mathrm{MC})$.

\section{Inadequacies in Internal Control of Enterprises}

\subsection{The Management of The Company Has A Vague Understanding of Internal Control and Insufficient Attention}

Some enterprises do not pay much attention to internal control, but pursue short-term economic benefits, production management and business work. They believe that internal control of enterprises is to develop internal control manuals and corresponding control systems, resulting in internal control systems flowing in form and text, and lost. The internal control should be severe and not play the role of internal control. In addition, the understanding of internal control is limited to internal accounting control. However, complete internal control includes accounting control and management control. Simple accounting control is not enough, although accounting control guarantees the security of property and the authenticity of accounting information. And integrity and the legality of financial activities, but companies also need management control to ensure the implementation of business 
policies, decision-making, and promote economic, efficiency, and effectiveness of business activities, in order to ensure the realization of business objectives.

\subsection{Lack of Risk Management of Internal Control}

The internal control work of an enterprise is too formalized and does not conform to the development of the enterprise itself. It is not involved in the enterprise risk management. Some enterprises often lack attention to ex ante control in internal control work, and more often implement post-event control, which greatly increases the risk management capability. At the same time, the company's own risk management level and technology are low, and there is a lack of scientific and systematic evaluation criteria to objectively evaluate risks. In addition, in the actual business process of the enterprise, the company's own risk management ideas are relatively lacking, and internal control management work is more It is a superficial effort and does not have strong risk management. Therefore, there is no excessive consideration and analysis of operational risks, and corresponding risk management measures are also lacking, which poses a certain threat to the business development of the enterprise.

\section{Improve Corporate Internal Control Initiatives}

\subsection{Establish a Basic Internal Control System Based on Business Requirements}

Each company has its own industry, scale, and nature of the company. Therefore, it is necessary to establish an internal control system based on its specific business conditions. In theory, the more links in the internal control system and the stricter the control measures and methods, the better the control effect, but the greater the cost. On the one hand, some links, measures or methods may not be necessary for enterprises. At this time, unnecessary resources may be consumed. On the other hand, it takes more costs than the basic system to establish a strict internal control system[3]. Therefore, enterprises can start from the internal control and internal accounting control at the most basic level. According to the key points of the business operation, the key points are controlled.

\subsection{Improve the Effectiveness of Internal Control Management Through Information Systems}

Establishing a risk internal control information system can improve the efficiency of internal control management and achieve a comprehensive landing of internal control. The establishment of risk internal control information system should be based on the high level of informationization of the enterprise as a whole and improve the efficiency of enterprise management by establishing numerous information systems, such as strategic management systems, quality management systems, production systems, etc., while providing basic data for internal control. information. On the basis of the mature operation of various information systems, the construction of risk internal control information system and the process form level control of various information systems can reduce the control cost and improve the control efficiency. Through the internal control information system construction, on the one hand, the internal control loopholes of the business system are compensated to ensure that the system can meet the requirements of internal control compliance, and on the other hand, the functions of risk explicitness and risk warning are realized, which provides fast and accurate decision-making for senior executives. The data and information provide good information support for the company to prevent risks from all angles.

\subsection{Strengthen Internal Audit and Supervision}

Enterprises need to improve the authority of the internal audit department by formulating forms, and clarify and fix their work content, establish complete internal audit rules and regulations, and at the same time, to achieve effective internal control and supervision, they can adopt internal and external forms. Select internal audit staff. In this "inside" is meant to rationally allocate the financial staff with higher internal quality to be responsible for the internal audit department; "outside" means 
to hire professional auditors from the social audit institution to take charge of the enterprise through recruitment. The internal audit work can promote the development of internal audit work[4].

In short, when competition is inevitable, in addition to actively responding to the challenges posed by rivals, in-depth research and discovery of complementary cooperation with competitors will help each other to learn from each other and turn disadvantages into positive factors. To make the market bigger is a feasible way.

Tab 1. Job responsibilities and qualification requirements of internal auditors

\begin{tabular}{|c|c|}
\hline Position Title & Internal Audit \\
\hline $\begin{array}{c}\text { Job } \\
\text { Responsibilities }\end{array}$ & $\begin{array}{c}\text { Comprehensive review of the completion of the annual responsibility target; } \\
\text { Responsible for organizing the annual, semi-annual and quarterly assessments of the } \\
\text { company and its affiliates } \\
\text { Responsible for the completion audit of the company's related projects; } \\
\text { Responsible for the departure audit of the company's leading cadres; } \\
\text { Formulate relevant internal audit systems and regulations; } \\
\text { Another internal audit works. }\end{array}$ \\
\hline Job requirements & $\begin{array}{l}\text { 1. Bachelor degree or above, major in auditing, finance, budget, accounting, etc.; } \\
\text { 2. Familiar with relevant national laws, regulations and policies, familiar with the } \\
\text { company's internal audit related system; skill extend all relevant software, budget software } \\
\text { and OA office systems: } \\
\text { 3. Strong communication and coordination skills, and a deep understanding of the audit } \\
\text { work; } \\
\text { 4. Relevant professional certificate; } \\
\text { More than } \\
\text { 5.1 years of internal audit related work experience; } \\
\text { 6. Work seriously and have a sense of responsibility. }\end{array}$ \\
\hline
\end{tabular}

\section{Conclusion}

Enterprises must balance the cost and benefit of internal control, find appropriate internal control input according to the company's own situation, and bring the maximum internal control effect with reasonable internal control input. While controlling the enterprise risk within a reasonable range, the enterprise is guaranteed. The goal of maximizing revenue is achieved.

\section{References}

[1]. Yang Jia. Discussion on internal control management and financial risk prevention in enterprises. China Foreign Investment, Vol. 9 (2013) No. 14, p. 177-179.

[2]. Xiao Luong. Enterprise internal control management and financial risk prevention. Enterprise Reform and Management, Vol. 7 (2016) No. 32, p. 115-119.

[3]. Fan Hui. Based on financial risk prevention within the enterprise Control Management Research. Finance and Economics (Academic Edition), Vol. 6(2014) No. 28, p. 164-170.

[4]. Bai Hongwei. Strengthening the internal control construction of enterprises to prevent enterprise risk research. New Economy, Vol. 21 (2013) No. 40, p. 59-62. 